\title{
Excessive Binding of Natural Anti-Alpha-Galactosyl Immunoglobin G to Sickle Erythrocytes May Contribute to Extravascular Cell Destruction
}

\author{
Uri Galili, Margaret R. Clark, and Stephen B. Shohet \\ MacMillan-Cargill Hematology Research Laboratory, Departments of Laboratory Medicine and \\ Medicine and Cancer Research Institute, University of California, San Francisco, California 94143
}

\begin{abstract}
A large proportion of sickle erythrocytes is removed from the circulation by the macrophages of the reticuloendothelial system. In view of the proposed role for natural antibodies in the destruction of normal senescent erythrocytes, we looked for a possible similarity in the antibodies that bind in situ to senescent and sickle cells. Bound IgG molecules were detected by a highly sensitive rosetting antiglobulin test, using $\mathrm{K} 562$ myeloid cells. After separation on Stractan density gradients, the $0.6 \%$ most dense (senescent) normal cells and the most dense $40 \%$ sickle cells displayed membrane-bound IgG as reflected by the high proportion of rosettes formed. No antibody was found on lowdensity cells of either type. The bound antibodies were readily eluted from both sickle and normal senescent cells by carbohydrates containing $\alpha$-galactosyl residues. These antibodies appear identical to the recently discovered human natural anti- $\alpha$ galactosyl IgG (anti-Gal), an IgG antibody present in high titers in normal sera. Moreover, affinity-purified anti-Gal interacted specifically with sickle and normal cells depleted of the autologous antibodies. A similar pattern of binding to the various erythrocyte subpopulations was observed when the radiolabeled lectin with anti- $\alpha$-galactosyl specificity, Bandeiraea simplicifolia, was used. In vitro phagocytosis of normal and sickle erythrocyte subpopulations correlated with the presence of anti-Gal on these cells. The in situ binding of anti-Gal to a large proportion of sickle erythrocytes may reflect an accelerated physiologic aging process by which immune recognition of prematurely exposed $\alpha$-galactosyl-bearing antigenic sites contributes to shortened cell survival.
\end{abstract}

\section{Introduction}

Direct measurements of erythrocyte survival in patients with sickle cell disease have shown a markedly decreased survival in the range of 10 to $30 \mathrm{~d}$ (1). The increased erythrocyte destruction takes place both intravascularly and extravascularly in the phagocytic cells of the reticuloendothelial system $(\operatorname{RES})^{1}(2,3)$.

This is publication no. 72 from the Macmillan-Cargill Hematology Research Laboratory.

Address correspondence to Dr. U. Galili, Cancer Research Institute, M-1282, University of California, San Francisco, CA 94143.

Received for publication 8 April 1985 and in revised form 14 August 1985.

1. Abbreviations used in this paper: anti-Gal, human natural anti- $\alpha-$ galactosyl IgG; BS, Bandeiraea simplicifolia; BSKG, buffered saline containing potassium and glucose; EA, erythrocyte antibody; ISC, irreversible sickle cells; RES, reticuloendothelial system; TPA, 10-O-tetradecanoyl phorbol ester.

J. Clin. Invest.

(c) The American Society for Clinical Investigation, Inc.

0021-9738/86/01/0027/07 \$1.00

Volume 77, January 1986, 27-33
Studies have provided evidence that phagocytosis of normal senescent human erythrocytes $(4,5)$, thalassemic cells $(6)$, or erythrocytes infected by malarial parasites (7) can be mediated by relatively small numbers of IgG molecules bound, in vivo, on the erythrocyte surface. In addition, Hebbel and Miller (8) have recently reported the presence of IgG molecules on high density sickle erythrocytes. They also showed that these antibodies induced the in vitro phagocytosis of the sickle cells by bone marrow and lung macrophages. In view of the similarities in the immunoglobulin-mediated phagocytosis of normal senescent erythrocytes and sickle erythrocytes, these investigators suggested that sickle cells may undergo an accelerated process of senescence, qualitatively similar to the aging of normal cells. In other studies, a natural antibody, human natural anti- $\alpha$-galactosyl IgG (anti-Gal), which shows specificity for the $\alpha$-galactosyl carbohydrate structure, was shown to bind in situ to high density normal erythrocytes and to thalassemic erythrocytes $(9$, 10). This antibody, which constitutes up to $1 \%$ of circulating IgG in every normal individual tested, does not recognize the T (Thompson-Friedenreich) antigen, which bears a terminal $\beta$ galactosyl residue. In addition, anti-Gal recognizes the specific linkage to the penultimate sugar, and binds specifically to $\mathrm{Gal} \alpha(1 \rightarrow 3) \mathrm{Gal}$ structures, but not to $\mathrm{Gal} \alpha(1 \rightarrow 4) \mathrm{Gal}$ (the P1 antigen epitope) or $\mathrm{Gal} \alpha(1 \rightarrow 3)[\mathrm{Fuc} \alpha(1 \rightarrow 2)] \mathrm{Gal}$ (the B blood group antigen) (11). Because the high density normal erythrocytes are thought to represent a senescent population $(12,13)$, the in situ binding of anti-Gal to these cells could play a role in their removal from the circulation. Our previous studies have indicated that the anti-Gal binding to senescent erythrocytes is mediated through the Fab portion of the antibody molecule (9), which implies the accessibility of the Fc portion of the bound anti-Gal for recognition by macrophages. To test the possibility that this same antibody might constitute the excess antibody found on sickle cells, we studied antibody binding to normal and sickle cells that had been separated into various age-related subpopulations by density gradient centrifugation $(12,13)$. The presence of IgG molecules on normal and sickle erythrocytes, and the antigenic specificity of the antibodies found on these two erythrocyte types were analyzed by using a sensitive rosetting antiglobulin test $(8-10,14,15)$. The results confirmed the presence of excess antibody bound to sickle cells. They further suggested that this antibody is indeed the same natural anti-Gal that binds to, and induces phagocytosis of, high density normal erythrocytes believed to be the senescent cells $(4,5,12,13)$. Finally, the increased binding of anti-Gal to sickle erythrocytes appears to be independent of the irreversible sickling phenomenon observed in this disease.

\section{Methods}

Erythrocytes and sera. Fresh citrated, heparinized or EDTA blood was obtained from normal donors and from 30 patients who had sickle cell anemia. None of the patients was transfused within 3 mo before analysis. 
Whole sickle blood samples contained 5 to $40 \%$ irreversible sickle cells (ISC). Sera were obtained from clotted blood of normal AB blood type individuals.

Erythrocyte separation on Stractan density gradients. For determination of antibody binding in erythrocyte subpopulations, samples of sickle and normal erythrocytes were separated using discontinuous Stractan density gradients (16). The gradients for these experiments consisted of five 1.5-ml layers, with densities of $1.081,1.085,1.094,1.107$, and $1.111 \mathrm{~g} / \mathrm{ml}$. These were layered on top of a cushion with a density of $1.160 \mathrm{~g} / \mathrm{ml}$ in $4 \mathrm{in} . \times 5 / 8 \mathrm{in}$. ultracentrifuge tubes. For each experiment, $2 \mathrm{ml}$ of whole blood was centrifuged down, the plasma was removed, and the cells were resuspended to a hematocrit of $20 \%$ or less in phosphatebuffered saline containing potassium and glucose (BSKG: $135 \mathrm{mM} \mathrm{NaCl}$, $5 \mathrm{mM} \mathrm{KCl}, 1.4 \mathrm{mM} \mathrm{NaH} \mathrm{PO}_{4}, 8.6 \mathrm{mM} \mathrm{Na}_{2} \mathrm{HPO}_{4}, 11 \mathrm{mM}$ glucose, adjusted to $\mathrm{pH} 7.4$ and $290 \pm 5 \mathrm{mosmol} / \mathrm{kg}$, as necessary). The cell suspension was then layered onto two identical gradients that were centrifuged for $30 \mathrm{~min}$ at 20,000 rpm (average force, 55,000 g). Successive populations of cells were harvested from the gradients using a Pasteur pipette and were then washed three times in BSKG. Aliquots of cells from each population were removed for determination of total cell numbers, percentage of reticulocytes, and percent ISC. Reticulocytes were stained using New Methylene Blue, and the cells were fixed in $0.5 \%$ glutaraldehyde in isotonic-buffered saline (American Scientific Products, McGraw Park, IL) for counting. Cells that were twice as long as they were wide, or that had distinctly angular contours, were counted as ISC. In the most dense, ISC-rich populations, there were often many cells that had abnormal shapes but did not meet these morphologic criteria for ISC. For these populations, the percentage of discoid, normally shaped cells was also determined. Total erythrocyte counts for each subpopulation were obtained using an electronic cell counter (model B; Coulter Electronics, Inc., Hialeah, FL).

Rosetting direct antiglobulin test with K562 cells. To detect the presence of antibody on erythrocytes a sensitive direct antiglobulin test was performed, according to the method previously described $(8-11,14,15)$. The detection of a small number of IgG molecules on the erythrocytes is based on the high affinity between the Fc portion of $\mathrm{IgG}$ molecules bound to the erythrocytes and the Fc receptors on the myeloid cell line K562. This interaction leads to the formation of erythrocyte-antibody (EA) rosettes. As we have previously shown $(14,15)$, in a control system of D-positive erythrocytes coated with anti-D antibodies, the proportion of rosettes was found to be related to the amount of bound antibody, in that the percentage of the rosetting K562 cells gradually decreased with increasing dilution of the anti-D serum. When comparing the rosetting and agglutination antiglobulin test in this system, the rosetting test was found to be several-fold more sensitive. Further, the rosetting test is highly specific, since D-negative cells formed no rosettes after incubation with anti-D antibodies (14). It should be stressed that the rosetting antiglobulin test reflects the presence of small amounts of bound IgG molecules, but like the standard agglutination antiglobulin test, does not provide quantitation of the bound antibodies. The assay was performed as a standard antiglobulin test except that, after incubation with specific rabbit anti-human IgG antibodies (Dako Corp., Santa Barbara, CA), the erythrocytes were washed twice with phosphate-buffered saline (PBS) and resuspended together with $0.1 \mathrm{ml}$ of $\mathrm{K} 562$ cell suspension $\left(1 \times 10^{6}\right.$ cells $/ \mathrm{ml}$ ). The mixed suspension was spun for $3 \mathrm{~min}$ at $200 \mathrm{~g}$ and incubated for $5-20 \mathrm{~h}$ at $4^{\circ} \mathrm{C}$. The pellet was gently resuspended, and the percentage of $\mathrm{K} 562$ cells binding the IgG-coated erythrocytes, and forming EA rosettes, was determined by counting $200-300 \mathrm{~K} 562$ cells in a hemocytometer. Rosettes were defined as $\mathrm{K} 562$ cells binding at least five erythrocytes. The assay was sufficiently sensitive to detect IgG molecules on red cells of patients considered to have Coomb's negative hemolytic anemias, such as thalassemia (10) and sickle cell anemia (8).

Carbohydrate elution of IgG bound to erythrocytes. To characterize the antigenic specificity of the antibody bound to the erythrocytes, IgGcoated erythrocytes were incubated in $100-\mathrm{mM}$ solutions of various carbohydrates (Sigma Chemical Co., St. Louis, MO) in PBS, pH 7.4, for $60 \mathrm{~min}$ at $37^{\circ} \mathrm{C}$. The anti-carbohydrate $\operatorname{IgG}$ molecules bound to the erythrocytes were eluted by an excess of carbohydrate with a structure corresponding to the antibody specificity. The erythrocytes were then washed twice to remove the eluted antibodies and tested for a decrease in the bound IgG by the rosetting antiglobulin test.

Isolation of anti-Gal from normal serum. This natural $\mathrm{IgG}$ antibody with distinct anti- $\alpha$-galactosyl specificity was isolated from normal $A B$ type human serum by affinity chromatography, as recently described (9). Briefly, $100-\mathrm{ml}$ volumes of heat-inactivated $\mathrm{AB}$ sera were loaded at $37^{\circ} \mathrm{C}$ onto 10 -ml melibiose ( $\alpha$-galactosyl-glucoside) Sepharose columns (Sigma Chemical Co.), expressing terminal $\alpha$-galactosyl residues. As an optional column, the SYNSORB $\alpha$-Gal (Chembiomed, Edmonton, Alberta, Canada) was used. The antibodies that were retained on the column after extensive washing ( 50 volumes) were eluted by $0.5 \mathrm{M}$ melibiose for $2 \mathrm{~h}$ at $37^{\circ} \mathrm{C}$. The carbohydrate was then removed by repeated dialysis against large volumes of PBS, and the anti-Gal IgG molecules were concentrated, employing a protein A Sepharose column (Sigma Chemical Co.) that binds IgG molecules via the Fc moiety. The antibodies were finally eluted from this column in a 5-ml volume of glycine- $\mathrm{HCl}$ buffer, pH 2.6, buffered, and dialyzed against PBS.

Binding of Bandeiraea simplicifolia (BS) lectin to density-separated erythrocyte subpopulations. The BS lectin is a plant lectin that was found to bind to various cell membrane glycoconjugates bearing terminal $\mathrm{Gal} \alpha(1 \rightarrow 3) \mathrm{Gal}$ residues, including human B blood type erythrocytes $(17$, 18). The lectin, purchased from Vector Laboratories, Inc. (Burlingame, CA), was radiolabeled with ${ }^{125}$ I using Bolton-Hunter reagent (New England Nuclear, Boston, MA). The specific activity obtained was $10^{6} \mathrm{cpm} /$ $\mu \mathrm{g}$. The lectin was brought to a concentration of $100 \mu \mathrm{g} / \mathrm{ml}$ in balanced salt solution. The labeling procedure did not affect the binding capacity of the lectin, since both the original and the labeled BS agglutinated rabbit erythrocytes, which bear an abundance of $\alpha$-galactosyl residues (11), down to a concentration of $0.05 \mu \mathrm{g} / \mathrm{ml}$. For erythrocyte labeling, $10-\mu \mathrm{l}$ aliquots containing $1 \mu \mathrm{g}{ }^{125} \mathrm{I}-\mathrm{BS}$ lectin were added to triplicate pelleted samples of $50 \times 10^{6}$ type $O$ erythrocytes. For assessment of nonspecific binding, the BS was added in a solution of $0.1 \mathrm{M}$ melibiose ( $\alpha$-galactosyl-glucoside). This carbohydrate prevents specific binding of BS to galactosyl residues. After incubation at $37^{\circ} \mathrm{C}$ for $60 \mathrm{~min}$, the erythrocyte suspensions were washed five times with PBS and transferred to new tubes for counting in a gamma counter. Specific labeling was calculated by subtracting cpm obtained in suspensions with melibiose from the cpm obtained in suspensions containing only the lectin.

In vitro erythrophagocytosis assay. To determine whether the presence of bound antibody promoted erythrophagocytosis, an in vitro phagocytosis assay was used, employing monolayer cultures of macrophages prepared from peripheral blood monocytes. Mononuclear cells obtained from heparinized blood by Ficoll-Hypaque sedimentation were washed, brought to a concentration of $2 \times 10^{6}$ in $1 \mathrm{ml}$ in RPMI 1640 (Gibco, Grand Island, NY), and supplemented with $2 \%$ heat-inactivated fetal calf serum. The cells were plated in $0.2-\mathrm{ml}$ flat-bottomed microwells (Nunc, Denmark). After 180 -min incubation at $37^{\circ} \mathrm{C}$, the nonadherent cells were removed, and the medium was replaced. Differentiation of the remaining adherent cells into phagocytic macrophages was promoted by incubation for 4-7 d in RPMI 1640 medium containing $1 \mu \mathrm{g} / \mathrm{ml} 10$ O-tetradecanoyl phorbol ester (TPA) (19). These cells displayed characteristics of macrophages, including phagocytosis of latex particles, Fc membrane receptors, and esterase staining. The phagocytosis assay was carried out according to the assay described by Kay (4). Erythrocytes $\left(10^{6} / \mathrm{ml}\right)$ in $0.2-\mathrm{ml}$ aliquots were incubated in triplicate with the macrophage monolayers for $20 \mathrm{~h}$. Erythrocytes that remained after this incubation were then counted in a hemocytometer, and the percentage phagocytized was determined, according to the formula $(a-b) / a \times 100$; where $a$ is the concentration of erythrocytes in control wells, and $b$ is the concentration of erythrocytes in macrophage-containing wells. Due to the limits of this assay, values of $<5 \%$ were regarded as background phagocytosis.

\section{Results}

Distribution of normal and sickle erythrocytes in a discontinuous Stractan gradient. As has been widely observed, the distributions 
of normal and sickle cells on the density gradients were substantially different from one another (Figs. 1, 2). In general, the sickle cell samples contained many more cells in the high density region of the gradients than did normal samples. The ISC were concentrated in the most dense bottom subpopulation (fraction VI). Although the densest cell populations were usually relatively depleted of reticulocytes, an occasional sample showed a substantial number of reticulocytes in even the most dense populations.

In addition to the greater abundance of very dense cells, the sickle cell samples also contained a low density population of cells not generally found in normal cell samples. The cells in this low density sickle population were not all reticulocytes. In fact, the reticulocyte percentages were sometimes lower than in the adjacent, higher density population that corresponded in density to the least dense normal populations. In addition, although the vast majority of ISC were found at high density positions, this lowest density population occasionally showed a slight elevation in the percentage of ISC, as compared with the other low density, ISC-poor populations.

Demonstration of IgG antibodies on normal and sickle erythrocytes. Density-separated erythrocytes from 10 normal individuals and 25 sickle cell anemia patients were assayed for bound IgG antibodies by the rosetting antiglobulin test. In the normal samples, no rosettes were found in fractions I-IV (for corresponding densities, see Fig. 1), which contained $>98 \%$ of the red cell population (Fig. 2). Whereas the erythrocytes in fraction $\mathrm{V}$ formed few rosettes, the small proportion of erythrocytes in fraction VI formed a reproducibly high percentage of rosettes, which suggests the presence of bound IgG antibodies



Figure 1. Distribution of representative normal and sickle erythrocytes on discontinuous Stractan gradients. The quantitative distributions for all subjects are graphed in Fig. 2.



Figure 2. Rosette formation by normal and sickle cell density gradient subpopulations. The level of antibody in each subpopulation is reflected by the percentage of rosettes formed with K 562 cells. The proportion of the total cells represented by each population is shown, and the fraction numbers indicate the cells' positions in the gradient as shown in Fig. 1. The values shown represent the mean \pm SE for 10 normal and 25 sickle cell subjects.

on these cells. The proportion of rosettes formed by sickle erythrocytes varied considerably for different patients, but was much higher than that observed in normal erythrocytes. Unseparated sickle cells formed 20-fold more rosettes than unseparated normal cells $(20 \%$ vs. $1 \%)$. When separated sickle cells were assayed, rosette formation was observed mostly in fractions IV, V, and VI, which composed $>30 \%$ of the sickle erythrocyte population. Although the proportion of rosettes varied considerably, fractions IV and V formed the highest proportions of rosettes, whereas the corresponding fractions in the normal erythrocyte population formed 0 and $15 \%$ rosettes, respectively. It should be stressed that in these 25 sickle patients, the proportion of ISC in the unseparated blood was $<20 \%$. In five patients displaying $>25 \%$ ISC, no rosettes were formed by the erythrocytes of the unseparated suspension, nor by the various density-separated subpopulations (data not shown).

$\alpha$-Galactosyl specificity of the IgG on normal and sickle erythrocytes. Previous studies have shown that IgG antibodies with distinct anti- $\alpha$-galactosyl specificity interact in vivo with pathologic thalassemic erythrocytes and with normal senescent erythrocytes $(9,10)$. To test the possibility that antibodies that bind to sickle cells and mediate the rosette formation had the same anti- $\alpha$-galactosyl specificity, elution experiments with various carbohydrates were performed, using cell populations that contained the bound antibodies, as indicated by the high proportion of rosette formation. As can been seen in Table I, the rosette formation by the sickle erythrocytes, as well as by the normal erythrocytes, was greatly decreased after incubation with $100 \mathrm{mM}$ galactose and to an even larger extent with the carbohydrates that contained $\alpha$-galactosyl residues, $\alpha$-methyl galactoside, and melibiose ( $\alpha$-galactosyl-glucoside). In contrast, lactose ( $\beta$-galactosyl-glucoside), glucose, and mannose were only marginally effective in reducing rosette formation by both types of cells. In particular, $\beta$-methyl galactoside was much less effective than $\alpha$-methyl galactoside or free galactose. Moreover, additional experiments showed that the natural anti-Gal isolated from normal AB sera readily bound to both senescent normal and sickle erythrocytes, when the cells were first incubated with melibiose (Table II). The binding of the anti-Gal to these cells represented a specific recognition of $\alpha$-galactosyl antigenic epitopes, as indicated by the selective inhibition of the interaction in the presence of melibiose, but not lactose (Table II). Further, the extent of anti-Gal binding obtained for the various sickle 
Table I. Alteration in Rosette Formation by Normal and Sickle Erythrocytes Incubated with Various Carbohydrates

\begin{tabular}{llccccccc}
\hline & \multicolumn{2}{l}{ Carbohydrate $(0.1 \mathrm{M})$} & & & \\
\cline { 2 - 8 } Erythrocytes & Saline & Galactose & Melibiose & Lactose & $\alpha$-Methyl-Galactose & $\beta$-Methyl-Galactose & Glucose & Mannose \\
\hline Normal, fraction VI & $48 \pm 7.3^{*}$ & $6 \pm 1.7$ & $2 \pm 0.6$ & $40 \pm 6.5$ & $3 \pm 0.8$ & $28 \pm 4.8$ & $45 \pm 7.8$ & $48 \pm 7.6$ \\
Sickle, fraction V & $55 \pm 3.9$ & $14 \pm 3.1$ & $9 \pm 2.6$ & $46 \pm 5.2$ & $10 \pm 4.8$ & $41 \pm 6.2$ & $40 \pm 6.9$ & $51 \pm 6.8$
\end{tabular}

* Percentage of rosettes with K562 cells after incubation of red cells with carbohydrates. Mean \pm SE of 10 different experiments.

and normal erythrocyte populations was comparable to the original level of bound antibody, as indicated by the rosetting antiglobulin test (Figs. $3 A$ and $B$ ). The rosette proportion after incubation with anti-Gal (Table II, Fig. 3) was usually somewhat higher than that observed in the original subpopulation, but this increase was not statistically significant.

In vitro phagocytosis of normal and sickle erythrocytes bearing the anti-Gal IgG. The relevance of the anti-Gal antibody in mediating the recognition of senescent normal and pathologic erythrocytes was assessed using in vitro phagocytosis experiments. Whereas considerable patient-to-patient variations were noted, the pattern observed was similar in all patients. The data of a representative normal individual, and that of a sickle cell patient are presented in Fig. 3. The extent of phagocytosis of the various density-separated erythrocyte subpopulations generally paralleled the presence of IgG molecules on both normal and sickle erythrocytes, except that intermediate density subpopulations that formed almost no rosettes did show a low level of phagocytosis. This may have reflected a greater sensitivity of the phagocytosis assay to the bound antibody, or a component of phagocytosis that is mediated by some other membrane change. No significant phagocytosis was observed in unseparated normal erythrocyte suspensions (data not shown). In addition, no spontaneous lysis was observed in the control wells lacking macrophages, since the erythrocyte concentration after 20-h incubation was identical to that originally plated.

Elution of the bound antibodies from dense erythrocyte subpopulations by incubation with melibiose markedly decreased the phagocytosis. High density cells, from which antibody had been eluted with melibiose, were then able to bind the purified

Table II. Effect of Anti-Gal on Rosette Formation by Erythrocytes Previously Depleted of Autologous Antibodies*

\begin{tabular}{lcr}
\hline Erythrocyte treatment & $\begin{array}{l}\text { Normal cells, } \\
\text { fraction VI }\end{array}$ & $\begin{array}{c}\text { Sickle cells, } \\
\text { fraction } \mathrm{V}\end{array}$ \\
\hline $\begin{array}{c}\text { Untreated } \\
\text { Incubation with melibiose }\end{array}$ & $\begin{array}{c}48 \pm 7.3 \ddagger \\
2 \pm 0.6\end{array}$ & $53 \pm 3.9$ \\
$\begin{array}{l}\text { Incubation with melibiose, then anti-Gal } \\
\text { Incubation with melibiose, then anti-Gal } \\
\quad+\text { melibiose 0.1 M }\end{array}$ & $62 \pm 4.1$ & $65 \pm 8.7$ \\
$\begin{array}{l}\text { Incubation with melibiose, then anti-Gal } \\
\quad+\text { lactose } 0.1 \mathrm{M}\end{array}$ & $13 \pm 3.4$ & $16 \pm 4.5$ \\
& $53 \pm 11.3$ & $57 \pm 10.9$ \\
\hline
\end{tabular}

* Melibiose concentration for elution of antibodies, $0.1 \mathrm{M}$. $\ddagger$ Percentage of rosettes with K562 cells, mean \pm SE of 10 different experiments.
anti-Gal. This interaction was specific to high density erythrocytes, which originally displayed in vivo bound antibodies. Low density fractions of erythrocytes subjected to similar incubation procedures with melibiose failed to bind the anti-Gal thereafter. The binding of anti-Gal to the high density subpopulations restored the in vitro phagocytosis of the cells of subpopulations that had undergone phagocytosis before antibody elution, both in normal and sickle erythrocyte populations. The low density subpopulations of both types did not bind the anti-Gal, and their phagocytosis was correspondingly low.

Binding of ${ }^{125} I$-Bandeiraea simplicifolia lectin to high density normal and sickle erythrocytes. The selective anti-Gal binding to high density subpopulations of normal and sickle erythrocytes implied the possible de novo exposure of terminal $\alpha$-galactosyl
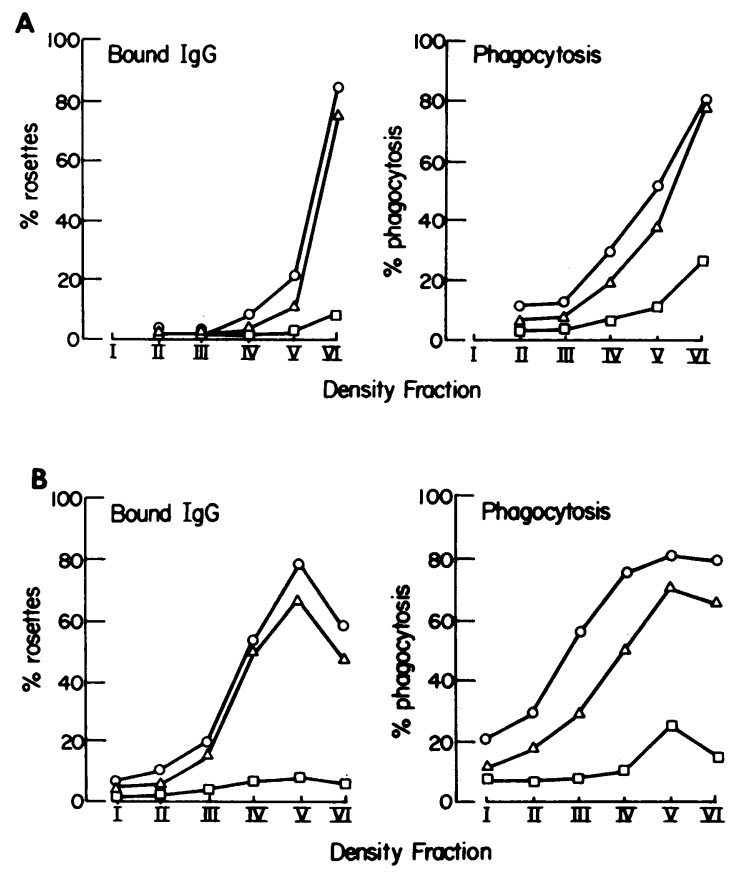

Figure 3. Correspondence between the rosette formation and in vitro phagocytosis for normal and sickle density-separated subpopulations. The level of IgG is reflected by the percentage of rosettes with K562 cells; phagocytosis is indicated by the percentage of erythrocytes destroyed during $20 \mathrm{~h}$ of incubation at $37^{\circ} \mathrm{C}$ over macrophage monolayers. The values shown are taken from one of five experiments that produced similar patterns. $A$, Normal erythrocytes; $B$, sickle erythrocytes. $\Delta$, Original erythrocyte subpopulation; $\square$, erythrocytes preincubated with melibiose $0.1 \mathrm{M} ; \circ$, erythrocytes preincubated with melibiose, washed, and then incubated with anti-Gal. 
residues on these cells. To obtain independent evidence for the exposure of such a carbohydrate entity, we assayed the various subpopulations of type $\mathrm{O}$ normal and sickle erythrocytes for the binding of the ${ }^{125} \mathrm{I}-\mathrm{BS}$ lectin, which specifically binds to $\mathrm{Gal} \alpha(1 \rightarrow 3)$ residues of glycoconjugates $(11,17,18)$. As described in Methods, this assay was performed after eluting any autologous anti-Gal by incubation of the erythrocytes with melibiose. The pattern of lectin binding in both normal and sickle cells was closely similar to that of the anti-Gal. That is, only $0.5-1 \%$ of the high density normal erythrocyte fraction VI exhibited specific binding, whereas the BS lectin interacted with fractions IV, V, and VI of sickle cells (Fig. 4). The observed binding on all of these populations corresponded to 500-1,000 BS lectin molecules per erythrocyte. In patients with high proportions of ISC ( $>25 \%$ ), no specific binding of the BS could be detected in the high density erythrocyte populations (not shown).

\section{Discussion}

Our observations indicate that a large proportion of sickle erythrocytes with a density higher than $1.094 \mathrm{~g} / \mathrm{ml}$ bind the natural anti-Gal in vivo. We assume that this represents the same phenomenon reflected in previous observations of bound antibody in high density sickle cell subpopulations (8). Although the antiGal IgG also binds in vivo to high density normal erythrocytes, the total proportion of sickle cells that carry bound antibodies is vastly larger than is found in normal blood. Whereas only $1 \%$ or less of normal cells have the antibody, $30-40 \%$ of sickle cells have it.

The observation that the most dense sickle cell populations that were rich in ISCs formed fewer rosettes than the next most dense, primarily discoid cells, was of some interest. This could have been because the marked rigidity of ISCs simply interferes with rosette formation. Studies with gradient-separated sickle cells coated with anti-D indicated, indeed, that ISCs form half the proportion of rosettes obtained with discoid cells coated with a comparable low amount of IgG (data not shown). We also noted no rosette formation by any of the subpopulations of cells from five patients who had high percentages of ISCs and reticulocytes, apparently associated with extremely rapid cell destruction. These same cell populations also failed to bind the BS lectin, which suggests that an absence of the antibody binding site, as well as impaired cell deformability, was responsible for the inability to form rosettes. These results are consistent with

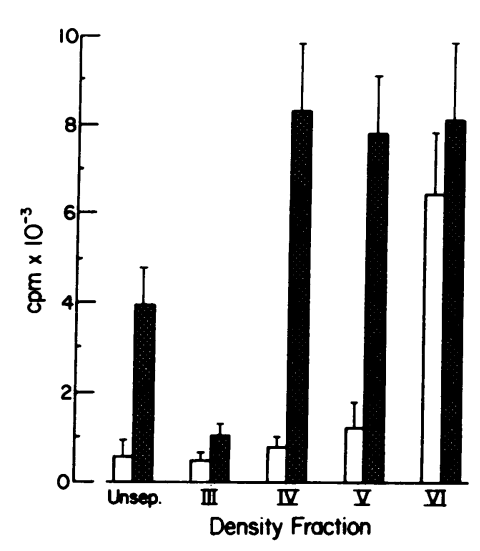

Figure 4. The binding of ${ }^{125}$ I-labeled Bandeiraea simplicifolia lectin to densityseparated type $O$, normal and sickle erythrocytes. Cells were preincubated with melibiose to remove autologous anti-Gal, and were then incubated with the lectin. Open bars indicate the levels of binding to normal cells; hatched bars, binding to sickle cells. The values represent the mean \pm SE for five normal and four sickle cell patients. a recent study by Petz et al. (20), in which bound IgG antibodies were found in only $70 \%$ of a larger group of patients. It may be that in these patients, erythrocytes are destroyed at an early stage by a nonimmunologic mechanism, before they bind detectable antibody.

By studying the effectiveness of various carbohydrates in eluting the antibody bound to the sickle cells, we were able to determine its antigenic specificity. As we had previously found for high density normal cells and for thalassemic cells $(9,10)$, the antibody binding showed a distinct specificity for the $\alpha$-galactosyl anomeric structure. This was shown in two ways: first, the antibody could be specifically eluted from the sickle cells by carbohydrates that contained an $\alpha$-galactosyl moiety, but not by other carbohydrates, including $\beta$-galactosyl oligosaccharides. Second, cells from which the antibody had been eluted were then able to bind the anti-Gal, previously shown to bind specifically to $\alpha$-galactosyl residues (11). The presence of anti- $\alpha$ galactosyl antibody in all normal sera studied was also recently demonstrated by other investigators. Bird and Roy (21) and Lalezari et al. (22) found anti-melibiose antibodies in normal sera, and Suzuki and Naiki (23) showed the binding of a natural IgG antibody to the Gal $\alpha(1 \rightarrow 3) \mathrm{Gal}$ containing rabbit ceramide pentahexoside. In our studies, incubation of antibody-depleted higher density cell subpopulations with affinity-purified anti-Gal resulted in a small, but consistent increase in rosette formation as compared with the original subpopulations. This may have been the result of the selection of high affinity anti-Gal antibodies in the course of the affinity chromatography purification. In these experiments, as before, the binding was specifically inhibited in the presence of melibiose.

The small number of binding sites for antibody, on both normal and sickle cells, complicates identification of the molecules on which the antigenic site resides. Petz et al. (20) have estimated that the level of antibody binding to sickle cells is on the order of only 200-600 molecules per cell, a quantity comparable to that estimated for high density normal cells by Kay (4) and Smalley and Tucker (24). In an attempt to define the antibody binding site(s) of normal dense cells, other investigators have proposed that it represents an altered form of an intrinsic membrane glycoprotein, possibly Band 3 protein $(25,26)$ or glycophorin (27). It is not yet clear whether the site to which the natural anti-Gal binds is the same site that has been studied by these other investigators, or whether antibodies with other specificities bind also to normal senescent and pathologic erythrocytes. Further work is needed to resolve these questions.

The exposure of the $\alpha$-galactosyl residues in high density normal and sickle erythrocytes was further demonstrated by the interaction between the lectin BS and type $O$ erythrocytes of various densities. As reported previously, this lectin agglutinates $B$ and $A B$ erythrocytes very strongly, $A$ cells weakly, and does not agglutinate $A_{2}$ or $O$ cells (28). Further analysis indicated that the BS lectin interacts specifically with $\mathrm{Gal} \alpha(1 \rightarrow 3)$ residues on various membrane molecules, as well as soluble glycoproteins $(11,17,18)$. In the present study, binding of the ${ }^{125}$ I-labeled lectin to type $O$ erythrocytes paralleled that observed with the purified anti-Gal. That is, BS lectin bound to the $<1 \%$ most dense normal cells, and to the $30-40 \%$ sickle cells in fractions IV, $\mathrm{V}$, and VI. The number of $\alpha$-galactosyl residues, as estimated from the lectin binding, was less than 1,000 per cell, on the average. This is consistent with estimates of antibody binding obtained previously $(4,20,24)$. It is of interest that no binding 
of the BS lectin could be demonstrated on the various subpopulations of erythrocytes from patients with high proportions of ISC that also failed to form rosettes.

The physiologic consequences of in vivo antibody binding to sickle and normal cells require further definition. There is currently some dispute as to whether the most dense normal erythrocytes are the oldest cells in the circulation. However, the presence on their surfaces of an antibody that promotes phagocytosis suggests that these cells are senescent, in the sense that they are approaching the end of their circulatory life span. In agreement with findings of other groups $(4,5,8)$, the specific in vitro phagocytosis of the high density normal and sickle erythrocytes corresponded with the presence of bound IgG molecules on these cells. The excessive phagocytosis observed in sickle erythrocytes depleted of autologous antibodies may be mediated by other membrane changes such as oxidative damage to membrane lipids that opsonize these cells for phagocytosis (8). Further support for the senescent nature of high density human erythrocytes can be taken from the observations of ten Brinke and de Regt (13), who showed that chromium-tagged, high density human erythrocytes had markedly shortened survival in vivo. If continued study confirms the senescent nature of high density normal cells, then the similarity of immunologically recognizable changes in these cells and in sickle cells supports the hypothesis that a large proportion of sickle cells undergoes an accelerated physiologic aging process. Further, the much greater proportion of sickle cells that binds the natural anti-Gal antibody suggests that this premature exposure of antigenic sites may play at least a partial role in the shortened life span of sickle cells. Another factor, however, which may contribute to the increased proportion of anti-Gal-bearing erythrocytes, may be a partial blockade of the RES due to the intensive phagocytosis of the pathologic erythrocytes $(2,3)$.

Perhaps more elusive than the identity of the anti-Gal binding site is the process by which the antigen exposure occurs. We have previously found that when low density normal cells lacking antibody binding sites are treated with pronase, they develop the capacity to bind anti-Gal (9). Thus, proteolytic cleavage of protein components on the cell surface could provide a means of antigen exposure. Since macrophages are known to secrete proteases (29), prolonged or repeated passage of erythrocytes through areas where macrophages are concentrated, such as the organs of the reticuloendothelial system, could provide an in vivo mechanism for cumulative proteolytic alteration of the cell surface. If such a process occurs in vivo, the impaired deformability of sickle cells might result in their detention in such areas, accelerating and augmenting the appearance of the putative senescence antigen. Certainly, other mechanisms for antigen exposure, such as oxidative damage to the membrane, or some sickling-associated damage, are also possible.

Further studies are needed to determine the identity of the binding site for anti-Gal and the mechanism of its exposure in both normal senescent and sickle cells. Nevertheless, the presence of the same antibody on both types of cells, and its effect in inducing their phagocytosis, suggest that a normal physiologic process for the removal of senescent erythrocytes contributes significantly to the destruction of sickle erythrocytes.

\section{Acknowledgments}

The authors are grateful to Dr. William Mentzer, Dr. William Lande, and Dr. Stephen Embury for supplying samples of sickle blood.
This work was supported in part by U. S. Public Health Service grants HL 20985, AM 32094, and AM 16095.

\section{References}

1. Besinger, E. A., and P. N. Gillette. 1974. Hemolysis in sickle cell disease. Arch. Intern. Med. 133:624-631.

2. Harris, J. W., H. H. Brewster, H. H. Ham, and W. B. Castle. 1956. Studies on the destruction of red blood cells. X. The biophysics and biology of sickle cell disease. Arch. Intern. Med. 97:145-168.

3. Bauer, T. W., W. Moore, and G. M. Hutchins. 1980. The liver in sickle cell disease: A clinicopathologic study of 70 patients. Am. J. Med. 69:833-837.

4. Kay, M. M. B. 1975. Mechanism of removal of senescent cells by human macrophages in situ. Proc. Natl. Acad. Sci. USA. 72:3521-3525.

5. Khansari, N., G. F. Springer, E. Merler, and H. H. Fudenberg. 1983. Mechanisms for removal of senescent human erythrocytes from circulation. Specificity of the membrane-bound immunoglobulin G. Mech. Aging Develop. 21:49-58.

6. Knyszynski, A., D. Danon, I. Kahane, and E. A. Rachmilewitz. 1979. Phagocytosis of nucleated and mature $\beta$-thalassemic red blood cells by mouse macrophages in vitro. Brit. J. Haematol. 43:251-262.

7. Jeje, O. M., J. G. Kelton, and M. A. Blajchman. 1983. Quantitation of red cell membrane-associated immunoglobulin with Plasmodium falciparum parasitemia. Br. J. Haematol. 54:567-572.

8. Hebbel, R. P., and W. J. Miller. 1984. Phagocytosis of sickle erythrocytes: immunologic and oxidative determinants of hemolytic anemia. Blood. 64:733-741.

9. Galili, U., E. A. Rachmilewitz, A. Peleg, and I. Flechner. 1984. A unique natural human IgG antibody with $\alpha$-galactosyl specificity. J. Exp. Med. 160:1519-1531.

10. Galili, U., A. Korkesh, I. Kahane, and E. A. Rachmilewitz. 1983. Demonstration of a natural anti-galactosyl IgG antibody on thalassemic red blood cells. Blood. 61:1258-1264.

11. Galili, U., B. A. Macher, J. Buehler, and S. B. Shohet. 1985. Human natural anti- $\alpha$-galactosyl IgG. II. The specific recognition of $\alpha(1 \rightarrow 3)$-linked galactose residues. J. Exp. Med. 162:573-582.

12. Piomelli, S., G. Lurinsky, and L. R. Wasserman. 1967. The mechanism of red cell aging. Relationship between cell age and specific gravity evaluated by ultracentrifugation in a discontinuous density gradient. J. Lab. Clin. Med. 69:659-674.

13. ten Brinke, M., and J. de Regt. 1970. ${ }^{51} \mathrm{Cr}$-half life time of heavy and light human erythrocytes. Scand. J. Haematol. 7:336-341.

14. Galili, U., N. Manny, and G. Izak. 1981. EA rosette formation: A simple means to increase sensitivity of antiglobulin test in patients with anti-red cell antibodies. Brit. J. Haematol. 47:227-233.

15. Sharon, R., and U. Galili. 1984. The rosetting antiglobulin test as a means of determining the D zygosity of human red cells. Vox. Sang. 46:175-179.

16. Corash, L., B. Shafer, and M. Perlow. 1978. Heterogeneity of human whole blood platelet subpopulations. II. Use of a sub-human primate model to analyze the relationship between density and platelet age. Blood. 52:726-734.

17. Eckhardt, A. E., and I. J. Goldstein. 1983. Isolation and characterization of a family of $\alpha$-galactosyl-containing glycolipids from Ehrlich ascites tumor cells. Biochemistry. 22:5290-5297.

18. Spiro, D. G., and V. D. Bhoyroo. 1984. Occurrence of $\alpha$-Dgalactosyl residues in the thyroglobulins from several species. Localization in the saccharide complex carbohydrate units. J. Biol. Chem. 259:98589866.

19. Phaire-Washington, L., E. Wang, and S. C. Silverstein. 1980. Phorbol myristate acetate stimulates pinocytosis and membrane spreading in mouse peritoneal macrophages. J. Cell Biol. 86:634-640.

20. Petz, L. D., P. Yam, L. Wilkinson, G. Garratty, B. Lubin, and W. Mentzer. 1984. Increased IgG molecules bound to the surface of red blood cells of patients with sickle cell anemia. Blood. 64:301-304. 
21. Bird, G. W., and T. C. Roy. 1980. Human serum antibodies to melibiose and other carbohydrates. Vox Sang. 38:169-171.

22. Lalezari, P., A. F. Jiang, M. Kumar, and I. Lalezari. 1984. Carbohydrate-specific antibodies in normal human sera. I. Characterization of specificity for $\beta$-D-glucose. Vox Sang. 47:133-145.

23. Suzuki, E., and M. Naiki. 1984. Heterophile antibodies in sera to rabbit erythrocytes and identification of the antigen as a glycolipid. J. Biochem. (Tokyo). 95:103-108.

24. Smalley, S. E., and E. M. Tucker. 1983. Blood group A antigen site distribution and immunoglobulin binding in relation to red cell age. Brit. J. Haematol 54:209-219.

25. Lutz, H. U., R. Flepp, and G. Stringaro-Wipf. 1984. Naturally occurring autoantibodies to exoplasmic and cryptic regions of band 3 protein, the major integral membrane protein of human red blood cells. J. Immunol. 133:2610-2618.

26. Kay, M. M. B., S. R. Goodman, K. Sorenson, C. R. Whitfield, P. Wong, L. Zakai, and V. Rudloff. 1983. Senescent cell antigen is immunologically related to band 3. Proc. Natl. Acad. Sci. USA. 80:16311636.

27. Alderman, E. M., H. H. Fudenberg, and R. E. Lovins. 1981. Isolation of an age-related antigen present on senescent red blood cells. Blood. 53:817-822.

28. Hayes, C. E., and I. J. Goldstein. 1971. An $\alpha$-D-galactosyl binding lectin from Bandeiraea simplicifolia seeds. Isolation by affinity chromatography and characterization. J. Biol. Chem. 249:1904-1914.

29. Reiko, T., and Z. Werb. 1984. Secretory products of macrophages and their physiological function. Am. J. Physiol. 246:C1-C9. 